\title{
Improved symptomatic, functional, and fluoroscopic outcomes following serial "series of three" double-balloon dilation for cricopharyngeus muscle dysfunction
}

\author{
Derrick R. Randall ${ }^{1} 2^{*}$, Lisa M. Evangelista', Maggie A. Kuhn ${ }^{1}$ and Peter C. Belafsky ${ }^{1}$
}

\begin{abstract}
Background: Cricopharyngeus muscle dysfunction (CPMD) is a common cause of dysphagia. We employ a progressive series of three double-balloon dilations separated by 4-6 weeks between procedures as a primary treatment option. The purpose of this study was to evaluate subjective, functional and objective improvement in swallowing after three serial dilations for CPMD.
\end{abstract}

Methods: We retrospectively evaluated patients between June 1, 2014, and June 30, 2016, who underwent a series of three double-balloon dilations for CPMD. Pre- and post-dilation Eating Assessment Tool-10 (EAT-10), Functional Oral Intake Scale (FOIS), pharyngeal constriction ratio, pharyngeal area, and pharyngoesophageal segment (PES) opening were compared.

Results: Seventeen patients with CPMD underwent serial double-balloon dilation procedures separated by one month. Mean age of the cohort was 73.5 (SD \pm 13.3 ) years, and 53\% were female. The mean EAT-10 improved from 24.7 (SD \pm 7.8$)$ to 15.9 (SD \pm 10.2$)[p=0.0021]$. Mean FOIS improved from $5.4(\mathrm{SD} \pm 1.4)$ pre- to 6.3 (SD \pm 0.9$)$ posttreatment $(p=0.017)$. Mean UES opening increased from $1.05(S D \pm 0.34) \mathrm{cm}$ to $1.48(S D \pm 0.41) \mathrm{cm}(p=0.0003)$ in the anteroposterior fluoroscopic view and from $0.58(S D \pm 0.18)$ to $0.76(S D \pm 0.30) \mathrm{cm}(p=0.018)$ in the lateral view. Pharyngeal constriction ratio $(P C R)$, a surrogate measure of pharyngeal strength, improved from $0.49(S D \pm 0.37)$ to $0.24(\mathrm{SD} \pm 0.15)(p=0.015)$, however pharyngeal area $(\mathrm{PA})$ was unchanged.

Conclusions: A progressive series of three double-balloon dilations for cricopharyngeus muscle dysfunction resulted in improved patient reported dysphagia symptom scores and objective fluoroscopic swallowing parameters.

Keywords: Dysphagia, Cricopharyngeus muscle dysfunction, Otolaryngology, Laryngology, Swallowing, Transnasal esophagoscopy

\section{Background}

Oropharyngeal swallowing dysfunction is common and costly. Complications include malnutrition, dehydration, depression, social isolation, pneumonia, hospital admission, increased length of stay, and death [1-3]. Early recognition allows implementation of appropriate rehabilitation, diet

\footnotetext{
* Correspondence: d.randall@ucalgary.ca

This manuscript was presented at the Canadian Society of Otolaryngology Annual Meeting, Charlottetown, PEI, June 11 - 14, 2016.

${ }^{1}$ Center for Voice and Swallowing, Department of Otolaryngology - Head \& Neck Surgery, University of California Davis, Sacramento, CA, USA

${ }^{2}$ Section of Otolaryngology - Head \& Neck Surgery, Department of Surgery, University of Calgary, Calgary, AB T2W 3K2, Canada
}

allocation or surgical management to prevent sequelae of impairment [4-6]. The pharyngoesophageal segment (PES) is a manometric high-pressure zone extending 3-5 cm from the hypopharynx to the cervical esophagus. Dysphagia resulting from PES dysfunction is a result of obstruction, poor compliance, impaired laryngeal elevation or ineffective pharyngeal propulsive forces [7]. Persons with PES dysfunction may present with solid food dysphagia, choking with deglutition, throat clearing, and globus.

One of the most common causes of solid food oropharyngeal dysphagia is cricopharyngeus muscle dysfunction (CPMD) [8]. The cricopharyngeus muscle is an essential

(C) The Author(s). 2018 Open Access This article is distributed under the terms of the Creative Commons Attribution 4.0 International License (http://creativecommons.org/licenses/by/4.0/), which permits unrestricted use, distribution, and 
component of the PES and is responsible for preventing the ingestion of air during respiration and reflux of esophageal contents into the pharynx. CPMD manifests as a spectrum of videofluoroscopic swallowing study (VFSS) findings ranging from non-obstructing bars found in up to $30 \%$ of the asymptomatic population to severely obstructing bars that limit oral intake to solids and liquids (Fig. 1) [9]. Pharyngeal constriction against an obstructed PES can lead to the development of a dilated, weak pharynx and Zenker's diverticulum $[10,11]$. Treatment options include diet modification, botulinum toxin injection, dilation and endoscopic or open myotomy [7]. A variety of procedural interventions have been demonstrated to improve both symptoms and radiographic evidence of CPMD [7, 12, 13]. The optimal treatment requires an individualized strategy that takes into account disease severity, patient comorbidities and functional status, prognosis and required duration of effect.

A recent systematic review of dilation for CPMD found a variable response rate, ranging from 64 to $100 \%$ [12]. The variability in treatment efficacy may be related to dilator size, number of procedures, and the underlying disease process [14-17]. Furthermore, measures of swallowing function can be assessed by one of the numerous dysphagia symptom indices, if at all, or objective outcomes from fluoroscopic investigations. In our center, we use a series of progressively enlarging balloon dilations, utilizing two balloons simultaneously to achieve a greater dilation profile and better approximate the natural, kidney shape of the PES $[18,19]$. Patients are asked to complete Eating Assessment Tool (EAT-10) and Functional Oral Intake Scale (FOIS) instruments at all patient encounters in order to measure their progress and assess the severity of their symptoms. The EAT-10 has been validated for impact on quality of life due to dysphagia for several different etiologies, while the FOIS evaluates the degree of oral diet capacity by considering variety of consistencies a patient can manage and the amount of enteral tube feeding required $[20,21]$. The purpose of this investigation was to determine the short term subjective and objective outcomes of serial PES double-balloon dilation for CPMD.

\section{Methods}

Patient population and outcome measures

This investigation was approved by the University of California, Davis Institutional Review Board (protocol \#905351-1). All patients with complete data who underwent a series of three progressively increased balloon dilations for CPMD between June 1, 2014, and June 30, 2016 were included. The diagnosis of CPMD was made on VFSS. Patients who had undergone intervention for CPMD prior to the VFSS and those with either Zenker

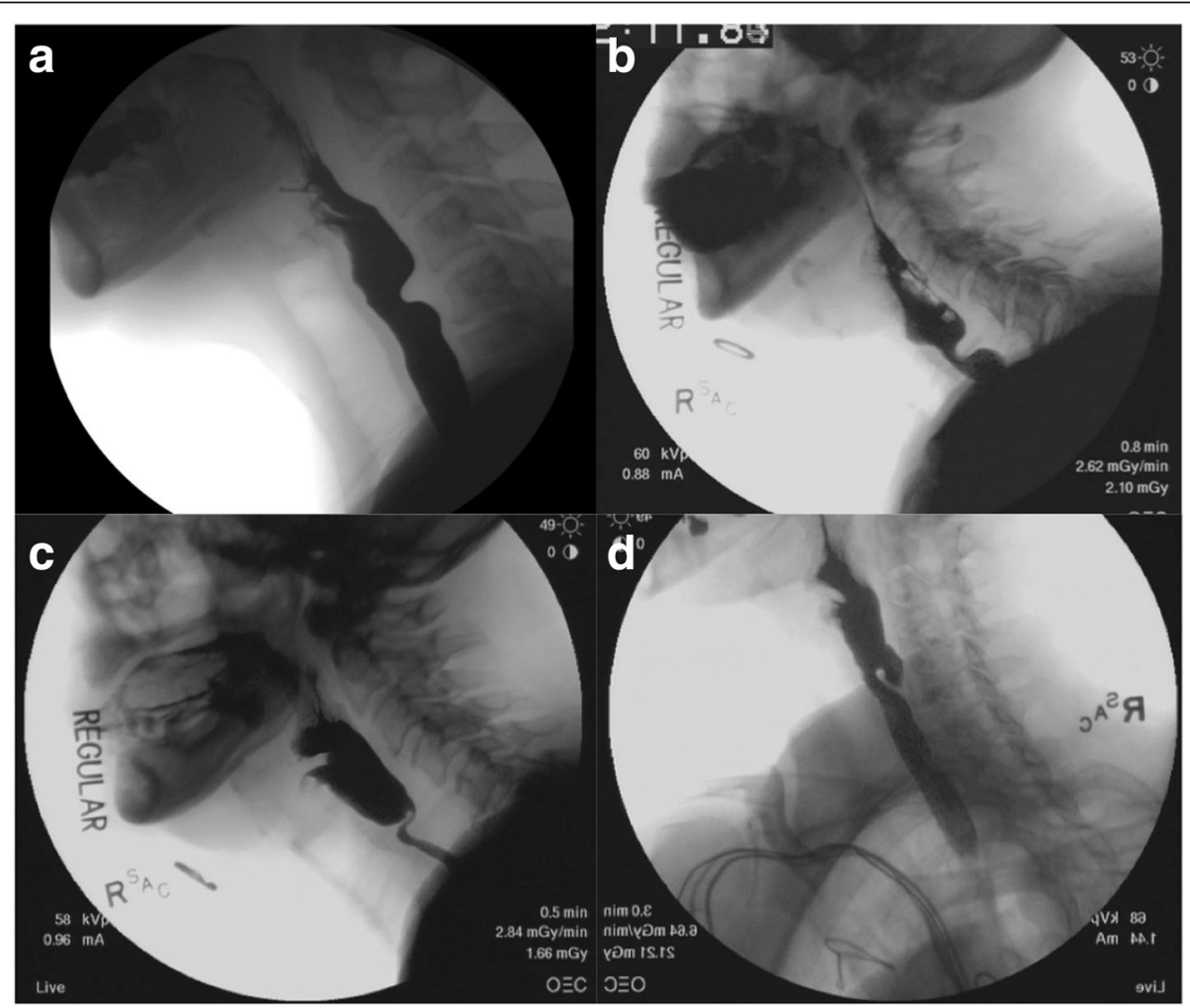

Fig. 1 Spectrum of cricopharyngeus muscle dysfunction showing asymptomatic narrowing of pharyngoesphageal segment to severe narrowing and diverticulum formation. a Non-obstructing bar. b Moderately obstructing bar. c Severely obstructing bar. d Zenker's diverticulum 
diverticulum or prior radiation therapy of the head and neck were excluded. Pre- and post-dilation validated EAT10, FOIS, PES opening $(\mathrm{cm})$ in the anteroposterior (PESAP) and lateral (PESL) fluoroscopic view (Fig. 2), pharyngeal constriction ratio (PCR), and pharyngeal area (PA) were retrospectively collected.

\section{Videofluoroscopic analysis}

Fluoroscopic studies were performed according to our center's standard protocol $[22,23]$. Each subject was administered a bolus of liquid barium (EZ-PAQUE barium sulfate suspension, $60 \% w / v ; 41 \% w / \mathrm{w}$, E-Z-EM, Inc., Westbury, NY) in the following order: 1,3 , and $20 \mathrm{~mL}$. Each subject was also given a $3-\mathrm{cm}^{3}$ bolus of barium paste (EZpaste, E-Z-Em, Inc). Patients undergoing esophagram did not receive a $3 \mathrm{~mL}$ bolus of liquid or paste barium but did additionally receive a $13 \mathrm{~mm}$ barium tablet and large volume $(>60 \mathrm{~mL})$ liquid barium trial via straw drinking. The fluoroscopic studies were recorded digitally with Olympus Image Stream Medical nStream G3 HD/SD Video Recording (Image Stream Medical, Littleton, MA) and were played back with WinDVD7 for Windows (Intervideo, Corel Corp., Ottawa, Canada).

Objective fluoroscopic displacement measures were obtained according to established protocols [9, 24-26]. In brief, pharyngeal area is measured in the lateral view on the $1 \mathrm{~mL}$ liquid barium 'hold' position. The posterior landmark starts superiorly at the posterior pharyngeal wall anterior to the tubercle of the atlas and follows inferiorly to the floor of the hypopharynx. The anterior boundary is traced from the posterior arytenoids to the surface of the arytenoid cartilages, proceeds to the laryngeal surface of the epiglottis, curves into the valleculae, then follows along the base of tongue. The anterior/superior landmark ends at the velum. All measures requiring lateral views utilize these landmarks. PCR is the ratio of PA at maximal compression divided by the PA at rest and is a validated measure of pharyngeal contractility. An elevated PCR suggests diminished pharyngeal strength [23]. Standardized measures of the PESL and PESAP were obtained during the trial of $20 \mathrm{~mL}$ liquid barium bolus. Anteroposterior (AP) measures for the UES opening are obtained in the AP view with the same superior and inferior landmarks; lateral boundaries are defined as the maximal distention.

\section{Surgical technique}

All dilation procedures were performed under monitored anesthesia care with sedation administered per anesthesiologist preference. Typical sedation is achieved with a combination of midazolam and fentanyl. Our technique of dilation begins with the administration of a combination xylocaine (4\%) and neosynephrine $(0.25 \%)$ nasal spray administered 2-3 min prior to the procedure. Flexible esophagoscopy is performed through the more patent naris (Pentax VE-1530 transnasal esophagoscope, Pentax Precision Medical Company, KayPentax, Lincoln Park, NJ, USA). A diagnostic esophagoscopy is performed and a guidewire(s) from a Hercules 3 Stage Wire Guided Balloon (Cook Medical, Bloomington, IN) is inserted through the side channel of the endoscope. The esophagoscope is then removed over the guidewire(s), replaced through the contralateral naris, and positioned in the hypopharynx to visualize the postcricoid region. The dilation balloon(s) are then advanced over the guidewire(s). Our protocol involves sequential

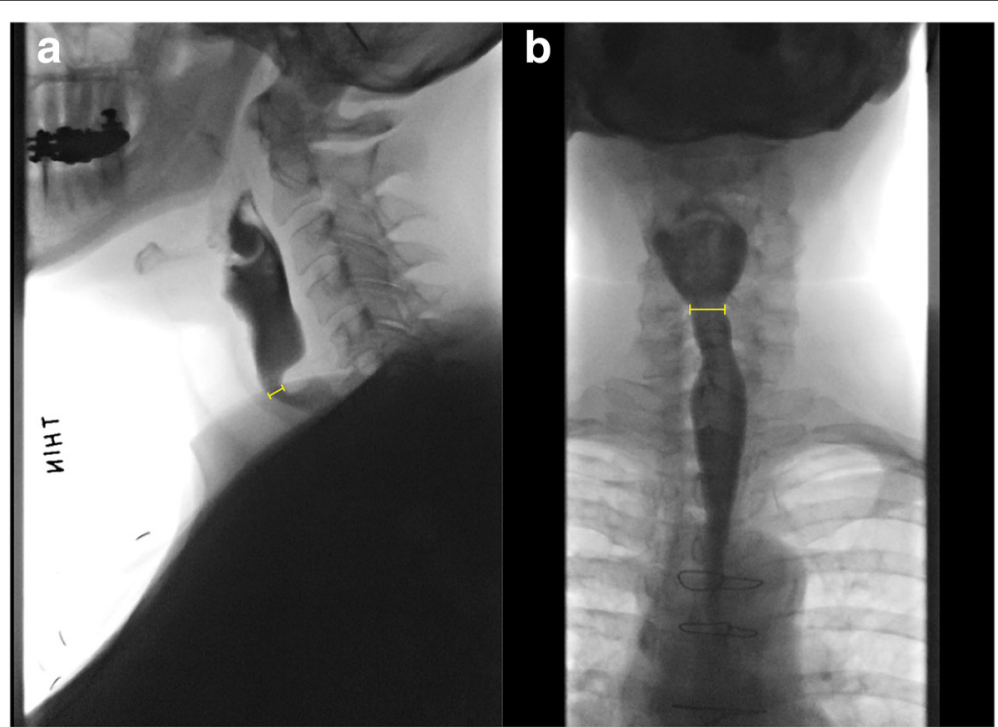

Fig. 2 Demonstration of pharyngoesophageal segment (PES) parameters in videofluoroscopy studies. a PES lateral view (PESL). b PES anteroposterior view (PESAP). Measurement bars indicate narrowest opening dimension during $20 \mathrm{~mL}$ barium volume test 
dilation personalized for each patient but typically begins with one 18-20 $\mathrm{mm}$ balloon in the first procedure, followed by two 13-15 mm balloons in the second dilation and two 15-18 $\mathrm{mm}$ balloons for the third dilation (Fig. 3). Balloons were sequentially inflated through each diameter and then held at final dilation for $60 \mathrm{~s}$. After deflation and removal, the PES was examined for signs of injury to the mucosa. The mucosa is examined at every stage of dilation and the procedure is terminated if any blood is seen on the balloon or evidence of mucosal laceration is visualized. The interval between dilations was 4-8 weeks, dependent on patient and OR availability, in accordance with use in prior studies [27, 28].

\section{Statistical analysis}

Statistical analysis was carried out using Stata 12.0 (StataCorp, College Way, TX), with descriptive statistics determined for baseline and demographic data. Comparison between pre- and post-dilation outcomes was performed using paired t-tests for continuous variables and Wilcoxon matched pairs-signed rank test for ordinal data. A Bonferroni correction was utilized to adjust for multiple comparisons.

\section{Results}

Seventeen patients with CPMD who underwent three serial balloon dilations with complete pre- and posttreatment fluoroscopy data were enrolled. The mean age of the cohort was 73 (SD \pm 11.5 ) years, $59 \%$ female. Fifty-one dilations were done in total. The mean duration between pre- and post-treatment VFSS was 206 $(\mathrm{SD} \pm 83)$ days and the mean time between final dilation and post-treatment fluoroscopy was $37(\mathrm{SD} \pm 33)$ days. Median balloon dilator diameters for the first, second, and third stages of the "series of three" dilations were $20 \mathrm{~mm}, 15+15 \mathrm{~mm}$, and $18+18 \mathrm{~mm}$, respectively, situated in the PES as shown in Fig. 3.

Changes in symptom and functional scores are displayed in Table 1. The mean EAT-10 improved from 24.
7 (SD \pm 7.8$)$ pre- to $15.9(\mathrm{SD} \pm 10.2)$ post-treatment $(p=0.0021)$. The mean FOIS improved from a mean of $5.4(\mathrm{SD} \pm 1.4)$ pre- to $6.3(\mathrm{SD} \pm 0.9)$ post-treatment $(p=$ 0.017). In our series, individual patient EAT-10 and FOIS scores either improved or were unchanged in 14/17 patients (82\%) following the third dilation, compared to pre-treatment values.

Changes in radiographic outcome are displayed in Table 2. PESAP increased from $1.05 \mathrm{~cm}(\mathrm{SD} \pm 0.34 \mathrm{~cm})$ to $1.48 \mathrm{~cm}(\mathrm{SD} \pm 0.41 \mathrm{~cm})(p=0.0003)$. PESL increased from $0.58 \mathrm{~cm}(\mathrm{SD} \pm 1.8 \mathrm{~cm})$ to $0.76 \mathrm{~cm}(\mathrm{SD} \pm 0.30 \mathrm{~cm})(p=0$. 018). These values represent increases in PES opening width and anteroposterior space of 41 and 31\%, respectively (Fig. 4). Among patients with severely obstructed CPMD (PESL opening less than $0.5 \mathrm{~cm}, n=7$ ) the anteroposterior opening increased by $72 \%$ from $0.39 \mathrm{~cm}(\mathrm{SD} \pm 0$. $07 \mathrm{~cm})$ to $0.67 \mathrm{~cm}(\mathrm{SD} \pm 0.27 \mathrm{~cm})(p=0.047)$. Patients who underwent serial balloon dilation also showed improvement in PCR from 0.49 (SD \pm 0.37 ) to $0.23(\mathrm{SD} \pm 0$. 15) $(p=0.015)$, indicating improved ability to constrict the pharynx and propel a food bolus through the PES. Despite improved constriction, PA showed no difference between pre- and post-treatment values $(p=0.91)$. There were no perforations of the upper esophagus or PES identified in this study cohort, and no patients developed delayed infections in the neck.

To evaluate the durability of our treatment approach, we reviewed patient records to determine whether members of our cohort underwent additional treatments. We identified ten patients (59\%) who underwent additional upper esophageal procedures, nine of whom had repeat dilations and one who opted for a cricopharyngeus myotomy. The mean duration of time between the third dilation and a repeat procedure was 416 days $(\mathrm{SD} \pm 246$, range $=124-849$ days). Five patients who underwent subsequent treatments also had fluoroscopic studies repeated, however there were no statistically significant differences between the measures obtained after the third dilation and the later dilation. Similarly, there were

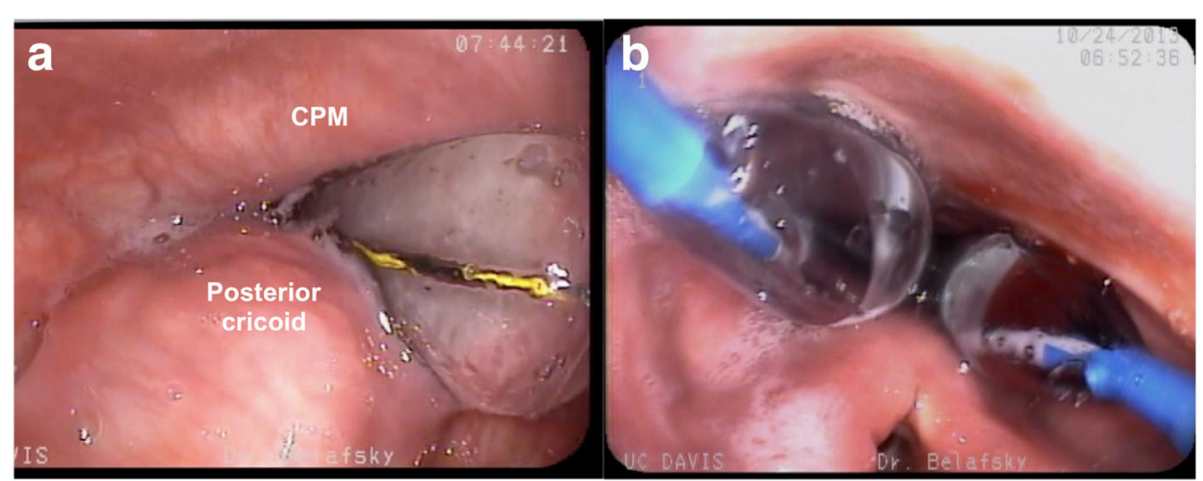

Fig. 3 Transnasal esophagoscope view of pharynx during sequential balloon dilation using a) one and b) two balloon dilators. $\mathrm{CPM}=$ cricopharyngeus muscle 
Table 1 Pre-and post-treatment symptom scale and functional outcome measures

\begin{tabular}{lllll}
\hline Parameter & $n$ & $\begin{array}{l}\text { Pre-treatment } \\
(+/- \text { SD })\end{array}$ & $\begin{array}{l}\text { Post-treatment } \\
(+/- \text { SD })\end{array}$ & $p$ value \\
\hline EAT-10 & 17 & $24.7(7.8)$ & $15.9(10.2)$ & $0.0021^{*}$ \\
FOIS & 17 & $5.4(1.5)$ & $6.3(0.9)$ & $0.017^{* *}$
\end{tabular}

EAT-10 eating assessment tool, FOIS functional oral intake scale

*Paired t-test

**Wilcoxon matched pairs-signed rank test

no differences between EAT-10 or FOIS scores $(n=9)$ following additional treatments.

\section{Discussion}

In this study, we investigated the effect of serial PES dilation for CPMD and report improved patient-reported symptoms, functional, and fluoroscopic short-term outcomes. We observed marked improvements in PES opening and EAT-10 scores, confirming existing data that PES dilation is an effective method to address CPMD [12]. Though symptom scores do not return to normal after intervention, they suggest significant improvement, which is compatible with measured fluoroscopic outcomes.

Our study provides several interesting findings related to the efficacy of serial double-balloon dilation to a size larger than what can be achieved with a single balloon. As expected, both PESAP and PESL opening increase in these patients but the increase is more pronounced in the anterior posterior projection (PESAP). The fluoroscopic finding of a hypertrophic cricopharyngeus muscle used to diagnose CPMD is typically identified on the lateral VFSS projection. We did not expect the greatest therapeutic benefit to be appreciated in the anteriorposterior fluoroscopic view (PESAP). Previous fluoroscopic data report improvement in the lateral fluoroscopic view only (PESL) $[10,16]$. Fig. 3 illustrates that the increased dilation obtained by using two balloons occurs in a vector that should increase the lateral dimension of the PES, a consequence that would result in improved opening on the AP VFSS. This degree of lateral expansion cannot be effectively achieved with a single, circular balloon or bougie.

Table 2 Pre-and post-treatment VFSS outcome measures. All tests performed with paired t-tests

\begin{tabular}{lllll}
\hline Parameter & $n$ & $\begin{array}{l}\text { Pre-treatment } \\
(+/- \text { SD) }\end{array}$ & $\begin{array}{l}\text { Post-treatment } \\
(+/-S D)\end{array}$ & $p$ value \\
\hline PESAP opening $(\mathrm{cm})$ & 15 & $1.05(0.34)$ & $1.48(0.41)$ & 0.0003 \\
PESL opening $(\mathrm{cm})$ & 17 & $0.58(0.18)$ & $0.76(0.30)$ & 0.018 \\
$\begin{array}{l}\text { Pharyngeal } \\
\text { constriction ratio }\end{array}$ & 13 & $0.49(0.37)$ & $0.24(0.15)$ & 0.015 \\
$\begin{array}{l}\text { Pharyngeal area }\left(\mathrm{cm}^{2}\right) \\
\text { P }\end{array}$ & 12 & $9.45(3.62)$ & $9.52(3.96)$ & 0.91 \\
\hline
\end{tabular}

PESAP upper esophageal sphincter in anterior-posterior view, PESL upper esophageal opening in lateral view
Anectodal experience and case reports indicate reflux symptoms can worsen following cricopharyngeus myotomy in select populations [29-31], leading some authors to consider reflux or ineffective esophageal motility a contraindication [32]. However, manometric studies of PES pressures before and after cricopharyngeus muscle myotomy demonstrate reduction of resting pressure to normal values with no increase in pharyngeal acid regurgitation [33-35]. The cricopharyngeus muscle is not ablated or resected with dilation, and it has been reported that single balloon dilation reduces the size of an obstructing cricopharyngeus muscle less than myotomy [10]. We observed persistent fluoroscopic indentation of the PES in most patients post serial dilations. This suggests that serial dilation may cause less diminution to the protective function of the PES than myotomy.

Another interesting observation was the disparate change in PCR and PA following serial PES dilation. While pharyngeal contraction improved (PCR), the pharynx remained dilated (PA). These data are consistent with other reports after both dilation and myotomy [10], which suggests that some of the pharyngeal dilation caused by prolonged PES obstruction may be permanent. A dilated pharynx is associated with decreased pharyngeal contractility and resting tone and is a major risk factor for aspiration. The finding that some of the pharyngeal insult caused by the CPMD is permanent may support earlier intervention before end stage pharyngeal dilation occurs. This is similar to findings in esophageal achalasia, which support LES intervention before the development of an atonic, dilated, sigmoid esophagus [36, 37].

This investigation is not without limitations. Definitive conclusions cannot be drawn from this retrospective case series. As with all musculotendinous injuries, return to function and rehabilitation is generally measured in months rather than days or weeks [38], which exceeds the mean duration between the final dilation and fluoroscopic assessment of 37 days. Thus, it is possible that the maximum amount of improvement was not captured. In addition, we were not able to determine improvements between dilation procedures, so it is not known at what point patients experienced the greatest improvement. Our clinical experience suggests that a series of three double-balloon dilations with a gradual increase in balloon diameter provides the safest most effective treatment strategy. Previous investigation has reported lateral fluoroscopic PES opening improvement to $0.62 \mathrm{~cm}$ after single balloon dilation and $0.82 \mathrm{~cm}$ after myotomy [10]. While the improvement to $0.76 \mathrm{~cm}$ reported in this investigation suggests that a series of three sequential dilations provides improved outcomes over a traditional single balloon procedure, a randomized prospective comparison is required before definitive improvement can be confirmed. This may prove difficult, as dilation is often reserved for elderly persons with significant medical comorbidity and myotomy recommended for younger, healthier 


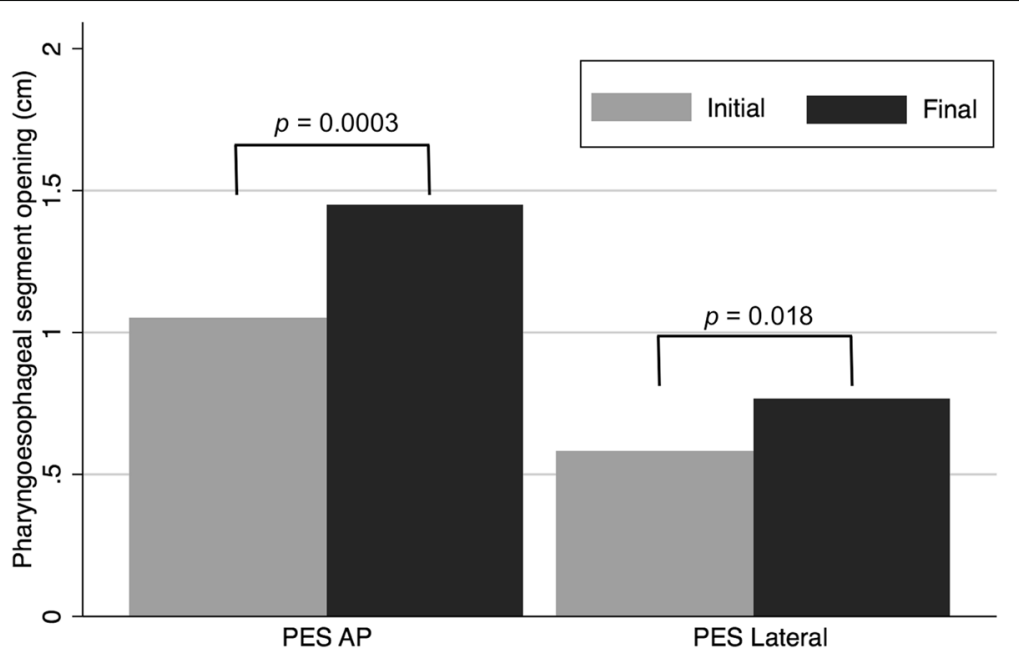

Fig. 4 Mean values of pre- and post-dilation opening dimensions of the pharyngoesphageal segment (PES). AP= anteroposterior view

individuals. This study was limited to persons with complete survey (EAT-10) and fluoroscopic data after three procedures. Individuals who experienced significant improvement after one or two dilations were excluded, as were individuals who were lost to follow-up or declined a postoperative fluoroscopic swallow study. The influence of this follow-up bias has an uncertain effect on the improvement reported in this investigation.

This investigation was designed to determine the shortterm symptomatic and objective outcomes of a series of three PES dilations. Previous investigations suggest there is inadequate long-term response following dilation to $20 \mathrm{~mm}$, particularly among persons with CPMD secondary to neurodegenerative disease such as oculopharyngeal muscular dystrophy [7, 39]. Ideally serial dilation would provide longer duration of benefit. We do not have patients routinely return for reassessment unless their symptoms recur, but our clinical experience with this technique suggests some patients develop symptomatic recurrence with less severe degree of cricopharyngeus muscle obstruction that responds to a single repeat treatment. We reviewed our cohort and found there was a subset of patients who returned for additional treatments. In this relatively small series, $59 \%$ of patients needed treatment again at a later date, on average 416 days after the third dilation. This is congruent with reported rates and timing of recurrence of swallowing dysfunction following dilation of the cricopharyngeus, but the heterogeneity of the data included in these studies makes direct comparison of any individual techniques difficult $[7,12,39]$. Indeed, recurrence and durability are important considerations in the management of CPMD and appropriate patient counseling, so rigorous future prospective investigation to properly address this question are needed. Defining recurrence based on either symptoms or objective data is challenging and varies between patients, so our study advances understanding in what outcomes can be expected.

Though serial double-balloon dilation is performed at numerous centers, there is little literature on its safety. The key complication or side effect of concern in these procedures is upper esophageal perforation. During the study period we did not have any perforations of the upper aerodigestive tract. Presumably the risk of perforation is increased with greater dilation diameter. Mucosal lacerations occurred in some instances, but this was not discretely recorded and could not be measured. In our experience, a simple mucosal laceration did not lead to any instances of deep neck space infections or other complications. Although we believe progressive dilation over three serial encounters with appropriate recovery intervals reduces the likelihood of this complication, further investigation is required to confirm this assertion. Optimal interval between dilations is debatable, with repeat dilations for benign mucosal strictures of the esophagus often done in weekly intervals, but we believe CPMD treatment allows longer intervals between treatments without losing efficacy, given the apparent average duration of effect [12, 27, 28, 40]. Even with the inherent limitations of this retrospective case series, the data suggest that a "series of three" dilation approach is a safe and effective treatment of cricopharyngeus muscle dysfunction and support the need for further study.

\section{Conclusion}

Our data suggest a "series of three" serial balloon dilation is a safe and effective treatment for CPMD. The treatment results in a significant improvement in symptomatic dysphagia (EAT-10), functional oral intake (FOIS), and objective fluoroscopic parameters. Further investigation is required to evaluate the durability and compare outcomes of this approach to traditional techniques of single balloon PES dilation. 


\section{Abbreviations}

CPMD: Cricopharyngeus muscle dysfunction; EAT-10: Eating Assessment Tool-10; FOIS: Functional Oral Intake Scale; PA: Pharyngeal area; PCR: Pharyngeal constriction ratio; PES: Pharyngoesophageal segment; PESAP: Pharyngoesophageal segment anteroposterior view; PESL: Pharyngoesophageal segment lateral view; SD: Standard deviation; VFSS: Videofluoroscopic swallowing study

\section{Acknowledgments}

The authors thank Sharon Clifford, Radiation Technologist, for image acquisition; Erik Steele, Anne Amador, Michelle Payne, Speech Language Pathologists, for fluoroscopy data collection analysis; Shannon Whitney, Barb Taylor, Mary Margaret Henson, Parul Puri, Registered Nurses, for data collection and operating room nursing; and Rebecca Anson, Surgical Scrub Technician, for operating room assistance.

\section{Availability of data and materials}

The datasets used and/or analysed during the current study are available from the corresponding author on reasonable request.

\section{Authors' contributions}

DRR developed study concept and protocol, obtained clinical data, analyzed and interpreted patient data, and was a major contributor in writing the manuscript. LME provided study design details, interpreted patient data, and performed fluoroscopic swallowing studies. MAK obtained clinical data, and was a major contributor in writing the manuscript. PCB obtained clinical data, analyzed and interpreted patient data, and was a major contributor in writing the manuscript. All authors read and approved the final manuscript.

\section{Ethics approval and consent to participate}

This investigation was approved by the University of California, Davis Institutional Review Board (protocol \#905351-1).

\section{Competing interests}

The authors declare that they have no competing interests.

\section{Publisher's Note}

Springer Nature remains neutral with regard to jurisdictional claims in published maps and institutional affiliations.

\section{Received: 13 November 2017 Accepted: 29 April 2018}

\section{Published online: 15 May 2018}

\section{References}

1. McHorney CA, Robbins J, Lomax K, Rosenbek JC, Chignell K, Kramer AE, et al. The SWAL-QOL and SWAL-CARE outcomes tool for oropharyngeal dysphagia in adults: III. Documentation of Reliability and Validity Dysphagia. 2002;17:97-114. https://doi.org/10.1007/s00455-001-0109-1.

2. Guyomard V, Fulcher RA, Redmayne O, Metcalf AK, Potter JF, Myint PK. Effect of dysphasia and dysphagia on inpatient mortality and hospital length of stay: a database study. J Am Geriatr Soc. 2009;57:2101-6. https:// doi.org/10.1111/j.1532-5415.2009.02526.x.

3. Altman KW, Yu G-P, Schaefer SD. Consequence of dysphagia in the hospitalized patient. Arch Otolaryngol Neck Surg. 2010;136:784. https://doi org/10.1001/archoto.2010.129.

4. Perry L, Love CP. Screening for dysphagia and aspiration in acute stroke: a systematic review. Dysphagia. 2001;16:7-18. https://doi.org/10.1007/ PL00021290

5. White GN, O'Rourke F, Ong BS, Cordato DJ, Chan DKY. Dysphagia: causes, assessment, treatment, and management. Geriatrics 2008;63:15-20. http:// www.ncbi.nlm.nih.gov/pubmed/18447407. Accessed 25 May 2017.

6. Altman K. Dysphagia evaluation and care in the hospital setting: the need for protocolization. Otolaryngol Head Neck Surg. 2011;145:895-8. https://doi. org/10.1177/0194599811415803.

7. Kuhn M, Belafsky P. Management of cricopharyngeus muscle dysfunction. Otolaryngol Clin N Am.2013;Dec;46:1087-99.

8. Hoy M, Domer A, Plowman EK, Loch R, Belafsky P. Causes of dysphagia in a tertiary-care swallowing center. Ann Otol Rhinol Laryngol. 2013;122:335-8. https://doi.org/10.1177/000348941312200508.
9. Leonard R, Kendall K, McKenzie S. UES opening and Cricopharyngeal bar in Nondysphagic elderly and nonelderly adults. Dysphagia. 2004;19:182-91. https://doi.org/10.1007/s00455-004-0005-6.

10. Allen J, White CJ, Leonard R, Belafsky PC. Effect of cricopharyngeus muscle surgery on the pharynx. Laryngoscope. 2010;120:1498-503. https://doi.org/ 10.1002/lary.21002

11. Belafsky PC, Rees CJ, Allen J, Leonard RJ. Pharyngeal dilation in cricopharyngeus muscle dysfunction and Zenker diverticulum. Laryngoscope. 2010;:NA-NA. doi:https://doi.org/10.1002/lary.20874.

12. Ashman A, Dale OT, Baldwin DL. Management of isolated cricopharyngeal dysfunction: systematic review. J Laryngol Otol. 2017;130:611-5. https://doi. org/10.1017/S0022215116007994.

13. Kocdor P, Siegel ER, Tulunay-Ugur OE. Cricopharyngeal dysfunction: a systematic review comparing outcomes of dilatation, botulinum toxin injection, and myotomy. Laryngoscope. 2016;126:135-41. https://doi.org/10. 1002/lary.25447

14. Wang AY, Kadkade R, Kahrilas PJ, Hirano I. Effectiveness of esophageal dilation for symptomatic cricopharyngeal bar. Gastrointest Endosc. 2005;61: 148-52. https://doi.org/10.1016/S0016-5107(04)02447-2.

15. Clary MS, Daniero JJ, Keith SW, Boon MS, Spiegel JR. Efficacy of largediameter dilatation in cricopharyngeal dysfunction. Laryngoscope. 2011;121: 2521-5. https://doi.org/10.1002/lary.22365

16. Dou Z, Zu Y, Wen H, Guifang W, Jiang L, Hu Y. The Effect of Different Catheter Balloon Dilatation Modes on Cricopharyngeal Dysfunction in Patients with Dysphagia. doi:https://doi.org/10.1007/s00455-012-9402-4.

17. Patel BJ, Mathur AK, Dehom S, Jackson CS. Savary dilation is a safe and effective long-term means of treatment of symptomatic Cricopharyngeal bar. J Clin Gastroenterol. 2013:1. https:/doi.org/10.1097/MCG.0000000000000026.

18. Cates D, Plowman EK, Mehdizadeh O, Yen K, Domer A, Gilden M, et al. Geometric morphometric shape analysis in an ovine model confirms that the upper esophageal sphincter is not round. Laryngoscope. 2013;123:7216. https://doi.org/10.1002/lary.23634.

19. Belafsky PC, Plowman EK, Mehdizadeh O, Cates D, Domer A, Yen K. The upper esophageal sphincter is not round: a pilot study evaluating a novel, physiology-based approach to upper esophageal sphincter dilation. Ann Otol Rhinol Laryngol. 2013;122:217-21. https://doi.org/10.1177/ 000348941312200401

20. Crary MA, Mann GDC, Groher ME. Initial psychometric assessment of a functional oral intake scale for dysphagia in stroke patients. Arch Phys Med Rehabil. 2005;86:1516-20. https://doi.org/10.1016/J.APMR.2004.11.049.

21. Belafsky PC, Mouadeb DA, Rees CJ, Pryor JC, Postma GN, Allen J, et al. Validity and reliability of the eating assessment tool (EAT-10). Ann Otol Rhinol Laryngol. 2008;117:919-24. https://doi.org/10.1177/ 000348940811701210

22. Leonard R, Belafsky P. Dysphagia following cervical spine surgery with anterior instrumentation: evidence from fluoroscopic swallow studies. Spine (Phila Pa 1976). 2011:36:2217-23. https://doi.org/10.1097/BRS Ob013e318205a1a7.

23. Randall DR, Strong EB, Belafsky PC. Altered pharyngeal structure and dynamics among patients with cervical kyphosis. Laryngoscope. 2016; https://doi.org/10.1002/lary.26417.

24. Kendall KA, McKenzie S, Leonard RJ, Gonçalves MI, Walker A. Timing of events in normal swallowing: a videofluoroscopic study. Dysphagia. 2000;15: 74-83. https://doi.org/10.1007/s004550010004.

25. Kendall KA, Leonard RJ. Pharyngeal constriction in elderly dysphagic patients compared with young and elderly nondysphagic controls. Dysphagia. 2001;16:272-8. https://doi.org/10.1007/s00455-001-0086-4.

26. Leonard R, Kendall KA, McKenzie S. Structural displacements affecting pharyngeal constriction in nondysphagic elderly and nonelderly adults. Dysphagia 2004;19:133-141. http://www.ncbi.nlm.nih.gov/pubmed/ 15382802. Accessed 25 May 2017

27. Francis DO, Hall E, Dang JH, Vlacich GR, Netterville JL, Vaezi MF. Outcomes of serial dilation for high-grade radiation-related esophageal strictures in head and neck cancer patients. Laryngoscope. 2015;125:856-62. https://doi. org/10.1002/lary.24987

28. Piotet E, Escher A, Monnier P. Esophageal and pharyngeal strictures: report on 1,862 endoscopic dilatations using the Savary-Gilliard technique. Eur Arch Oto-Rhino-Laryngology. 2008:265:357-64. https://doi.org/10.1007/ s00405-007-0456-0.

29. van Overbeek JJ, Betlem HC. Cricopharyngeal myotomy in pharyngeal paralysis. Cineradiographic and manometric indications. Ann Otol Rhinol 
Laryngol. 1979;88(5 Pt 1):596-602. https://doi.org/10.1177/ 000348947908800503

30. Bonavina L, Khan NA, DeMeester TR. Pharyngoesophageal dysfunctions. The role of cricopharyngeal myotomy. Arch Surg 1985;120:541-549. http://www. ncbi.nlm.nih.gov/pubmed/3921004. Accessed 25 May 2017.

31. Sanei-Moghaddam A, Kumar S, Jani P, Brierley C. Cricopharyngeal myotomy for cricopharyngeus stricture in an inclusion body myositis patient with hiatus hernia: a learning experience. BMJ Case Rep. 2013;2013 https://doi. org/10.1136/bcr-2012-008058.

32. Kelly JH. Management of upper esophageal sphincter disorders: indications and complications of myotomy. Am J Med. 2000;:43S-46S. http://www.ncbi. nlm.nih.gov/pubmed/10718451. Accessed 25 May 2017.

33. Taillefer R, Duranceau AC. Manometric and radionuclide assessment of pharyngeal emptying before and after cricopharyngeal myotomy in patients with oculopharyngeal muscular dystrophy. J Thorac Cardiovasc Surg 1988;95:868-875. http://www.ncbi.n/m.nih.gov/pubmed/3361934. Accessed 25 May 2017.

34. Pera M, Yamada A, Hiebert CA, Duranceau A. Sleeve recording of upper esophageal sphincter resting pressures during Cricopharyngeal Myotomy. Ann Surg. 1997;225:229-34. https://doi.org/10.1097/00000658-19970200000012.

35. Williams RBH, Ali GN, Hunt DR, Wallace KL, Cook IJ. Cricopharyngeal myotomy does not increase the risk of esophagopharyngeal acid regurgitation. Am J Gastroenterol. 1999:94:3448-54. https://doi.org/10.1111/j. 1572-0241.1999.01507.x.

36. Gyawali CP. Achalasia: new perspectives on an old disease Neurogastroenterol Motil. 2016;28:4-11. https://doi.org/10.1111/nmo.12750.

37. Roman S, Kahrilas PJ, Mion F, Nealis TB, Soper NJ, Poncet G, et al. Partial recovery of peristalsis after myotomy for achalasia: more the rule than the exception. JAMA Surg. 2013;148:157-64. https://doi.org/10.1001/2013. jamasurg.38.

38. Kuhn JE. Exercise in the treatment of rotator cuff impingement: a systematic review and a synthesized evidence-based rehabilitation protocol. J Shoulder Elb Surg. 2009;18:138-60. https://doi.org/10.1016/j.jse.2008.06.004.

39. Manjaly JG, Vaughan-Shaw PG, Dale OT, Tyler S, Corlett JCR, Frost RA. Cricopharyngeal dilatation for the long-term treatment of dysphagia in Oculopharyngeal muscular dystrophy. Dysphagia. 2012;27:216-20. https:// doi.org/10.1007/s00455-011-9356-y.

40. Bilgin Buyukkarabacak Y, Taslak Sengul A, Pirzirenli MG, Basoglu A. Recurrent dilatation in resistant benign esophageal strictures: timing is significant. Turkish J Med Sci. 2016;46:79-83. https://doi.org/10.3906/sag-1412-72.

\section{Ready to submit your research? Choose BMC and benefit from}

- fast, convenient online submission

- thorough peer review by experienced researchers in your field

- rapid publication on acceptance

- support for research data, including large and complex data types

- gold Open Access which fosters wider collaboration and increased citations - maximum visibility for your research: over $100 \mathrm{M}$ website views per year

At BMC, research is always in progress.

Learn more biomedcentral.com/submissions 